\title{
Bicalutamide/Leuprolide Regimen
}

National Cancer Institute

\section{Source}

National Cancer Institute. Bicalutamide/Leuprolide Regimen. NCI Thesaurus. Code C10701.

A regimen consisting of bicalutamide and leuprolide acetate that may be used in the treatment of certain types of prostate cancer. 